\title{
Friction reduction efficiency of organic Mo-containing FM additives associated to ZDDP for steel and carbon-based contacts
}

\author{
O. Gorbatchev ${ }^{\mathrm{a}}$, M.I. De Barros Bouchet ${ }^{\mathrm{a}}$, J.M. Martin ${ }^{\mathrm{a}}$, D. Léonard ${ }^{\mathrm{b}}$, T. Le-Mogne ${ }^{\mathrm{a}}$, \\ R. Iovine ${ }^{\mathrm{c}}, \mathrm{B}$. Thiebaut ${ }^{\mathrm{c}}, \mathrm{C}$. Héau ${ }^{\mathrm{d}}$ \\ a Université de Lyon, Laboratoire de Tribologie et Dynamique des Systèmes, CNRS UMR5513, 69134 Ecully, France \\ ${ }^{\mathrm{b}}$ Université de Lyon, Institut des Sciences Analytiques, CNRS UMR 5280, 69100 Villeurbanne, France \\ ' TOTAL, Solaize Researcher Center, BP22-69360 Cedex, France \\ d IREIS, Rue Benoît Fourneyron, 42160 Andrézieux-Bouthéon, France
}

\begin{abstract}
The lubricating properties of two different organomolybdenum additives combined with ZDDP were evaluated for different tribopairs involving carbon-based coatings, hydrogenated DLC and nanocrystalline diamond NCD. Their performances were investigated using reciprocating linear tribometer and compared with the traditional additivation MoDTC/ZDDP. The highly sulfurised moly-trimer additive and organic molybdate ester additive displayed good friction reducing properties in comparison with traditional additivation MoDTC for all tribopairs tested, especially organic molybdate ester. XPS and ToFSIMS surface analyses performed on the tribofilms formed with these different organomolybdenum additives showed the formation of $\mathrm{MoS}_{2} / \mathrm{MoS}_{2-x} \mathrm{O}_{x}$ species exhibiting a solid lubricant character, but preferentially on steel surfaces. HRTEM/EDS analyses confirmed the presence of $\mathrm{MoS}_{2} / \mathrm{MoS}_{2-x} \mathrm{O}_{x}$ sheets embedded inside an oxygen-rich amorphous matrix. This is different from the traditional additivation that leads to the polyphosphate/phosphate glass matrix. Organic molybdate ester is a sulfur- and phosphorus-free additive that appears particularly interesting for achieving low friction while minimizing the $\mathrm{S}$ content of the lubricant.
\end{abstract}

\section{Introduction}

Due to the depletion of energy reserves and high demand of low gas emission to preserve the environment and people's health, friction reduction of machine parts is increasingly required. Liquid lubricants formulated with friction modifier and anti-wear additives are commonly used to achieve this goal. Under low and moderate contact pressures, polar molecules like carboxylic acids, esters and fatty acids, adsorb onto metallic surfaces building a low-shear molecular tail that avoids asperity contact and makes easier the sliding motion. As the contact conditions become more severe, a higher number of asperities come into contact and, under such boundary lubrication conditions, stronger protection is needed. This is commonly achieved by more adherent chemicallyformed organometallic films that limit friction and wear [1-6].

Molybdenum-based FM additives have been widely studied during the last decades due to their well-known friction reducing properties related to their capacity to form $\mathrm{MoS}_{2}$ lamellar structure providing low-shearing under high contact pressure [7-11]. The most widely investigated soluble molybdenum-based molecules are dithiocarbamates (MoDTC) and dithiophosphates (MoDTP), used alone or synergistically combined with well-known anti-wear and antioxidant additive dialkyldithiophosphates (ZDDP) [12-14]. Despite really interesting friction reduction properties for steelbased surfaces, Mo-based molecules suffer from non-complete sulfuration process leading to the formation of molybdenum oxides $\left(\mathrm{MoO}_{x}\right)$ and oxisulfides $\left(\mathrm{MoS}_{2-x} \mathrm{O}_{x}\right)$ species $[14,15]$. They also suffer from rapid thermal decomposition and/or ageing effect in the oils shortening their durability and friction reduction efficiency [16-18].

On the other hand, other tribological materials such as diamondlike carbon (DLC) coatings have been recently proposed to go further in friction reducing level under different lubrication regimes, and more specifically mixed and boundary conditions. MoDTC performance has then been investigated on different types of DLCs and results showed that this kind of coatings can improve the friction reduction and wear-resistance for DLC/DLC tribo-pairs but it is not always the case for DLC/steel contacts due to the severe chemical wear that can occur with that configuration [19-24].

In this overall context, it is not surprising that recent investigations were made on different soluble friction modifying Mobased compounds for tribological applications. Hu et al. [25] synthesized recently sulfur and phosphorous-free organic molybdate esters more stable in temperature and they reported good anti-wear and friction-reduction performances for steel/steel 
contact when it was synergistically associated with ZDDP. Other authors have also reported the interesting anti-wear abilities of such $\mathrm{S}$ and P-free compounds at different loads, especially at high loads [26,27]. On the other hand, highly sulfurised molybdenum dithiocarbamates (without oxygen atoms) were produced like moly-trimer $\mathrm{Mo}_{3} \mathrm{~S}_{7}(\mathrm{DTC})_{3}$. It is interesting to evaluate their friction and wear reducing properties in different tribological contacts involving carbon-based materials. For these highly sulfurised compounds, the formation of abrasive Mo-oxides is not expected and production of lamellar $\mathrm{MoS}_{2}$ species is certainly favorized $[28,29]$. These oxides being often suspected to be involved of the strong wear of DLC coatings [19-22,30], a strong benefit can then be expected with this moly-trimer.

In this work, we investigated the lubricating mechanism of two different friction modifying molybdenum-based compounds coupled to the traditional anti-wear additive ZDDP for three different friction pairs. The first one is a highly sulfurised moly-trimer and the second one is a more environmentally friendly S-and P-free organic molybdate ester. The well-known MoDTC friction modifier is also studied as a reference.

To better understand the tribochemical mechanisms of these soluble Mo-containing molecules in the presence of ZDDP, we analyzed the chemistry of these compounds in the liquid phase by X-ray Photoelectron Spectroscopy (XPS), first alone and in the binary mixtures with ZDDP. The chemistry of tribofilms formed in the presence of these binary mixtures on different sliding contacts was investigated by XPS and complementary information was obtained from ToF-SIMS analysis. The structure of these tribofilms and their interface with the substrate were revealed by TEM coupled to EDS using cross-sections nanomachined by the FIB technique. The originality of this study lies also in the fact that tribofilms were generated with three different friction pairs, namely steel/steel, hydrogenated DLC (a-C:H/steel) and steel/ nano-crystalline diamond (NCD). These carbon-based coatings can be used in different contact pressure applications such as valvetrain lifters, piston rings or bearings.

\section{Experimental details}

\subsection{Additives and lubricants}

Two base oils (a synthetic PAO4 and a mineral GrIII of similar dynamic viscosity $4.9 \times 10^{-3}$ Pa s at $353 \mathrm{~K}$ ) and the different additives considered in this work were supplied by TOTAL M\&S. It should be noted that the representations of the additive molecules given in Fig. 1 are only schematic. The production processes of these molecules give raw materials with variable chain lengths and partial sulfuration do not guarantee very high purity according to the supplier.

The high sulfurized moly-trimer additive developed by Infineum [31] is called " Mo-tri-nuclear " in the following, its chemical formula is shown in Fig. 1a. This additive is promising because it contains an amount of sulfur greater than that in the well-known moly-dimer MoDTC and it is theoretically free of oxygen. The second organic molybdate ester additive free of $\mathrm{S}$ and $\mathrm{P}$ developed by Vanderbilt [32] is called "Mo-organic " in the following, the chemical schematic formula of which is shown in Fig. 1b. This additive is sulfur free allowing the decrease of the overall sulfur concentration in a binary with ZDDP antiwear additive, when compared to binary mixtures with MoDTC or Mo tri-nuclear. Considering that in lubricant formulations, concentration of molybdenum for both systems is constant $(400 \mathrm{ppm})$, the use of Mo-organic compound reduces the overall sulfur content by about $20 \%$.

Binary mixtures composed of $400 \mathrm{ppm}$ of Mo-based additive plus 1wt\% of ZDDP (II) (synthetized from 1-3-dimethyl buthyl and

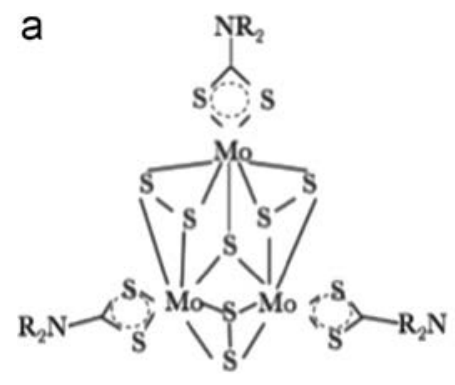

b<smiles>O=C(c1ccccc1)N1CCO[Y9](=O)(=O)O1</smiles>

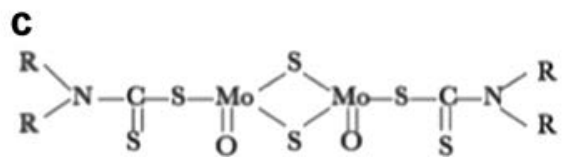

Fig. 1. (a) Chemical formula of the moly-trimer (Mo tri-nuclear). (b) Chemical formula of the organic molybdate ester (Mo-organic) (c) Chemical formula of the moly-dimer (MoDTC).

isopropyl and contained about $10 \%$ of $\mathrm{Zn}$ ) were obtained by stirring and heating to $60{ }^{\circ} \mathrm{C}$ for $20 \mathrm{~min}$. Similar binary mixture was performed with traditional MoDTC additive shown in the Fig. 1c.

\subsection{Carbon-based materials}

In house NCD coatings were deposited on a Ti-6Al-4V flat substrate thanks to the PECVD process at moderate temperature, equal to or lower than $600{ }^{\circ} \mathrm{C}$. from $\mathrm{CH}_{4} / \mathrm{CO}_{2}$ species [33]. Among the various NCD coatings that can be elaborated [34], a fairly good NCD coating combining high diamond purity, low surface roughness and excellent mechanical properties was selected for this work (see Table 1). Due to the high wear resistance of this kind of coating, its thickness was fixed to about $1.4 \mu \mathrm{m}$ as estimated from FIB/TEM.

Industrial DLC coating containing hydrogen, a-C:H was also investigated in this work in order to observe the influence of amorphous carbon matrix and $\mathrm{sp}^{3} / \mathrm{sp}^{2}$ carbon ratio on the lubricated tribological behavior. It was deposited on AISI 52100 bearing steel (96.9 wt\% Fe, $1.04 \mathrm{wt} \%$ C, $1.45 \mathrm{wt} \% \mathrm{Cr}, 0.35 \mathrm{wt} \% \mathrm{Mn}$ and $0.27 \mathrm{wt} \% \mathrm{Si}$ ) using a PECVD process and provided by IREIS Company. In that case, the a-C:H coating was deposited on a steel ball with a thickness of about $4.5 \mu \mathrm{m}$ as indicated in Table 1 that compares the properties of amorphous and NCD carbon-based coatings.

\subsection{Tribological experiments}

A linear reciprocating friction tribometer with a ball-on-flat configuration was used to generate tribofilms in mild/severe tribological conditions (sinusoidal motion). Three friction configurations were selected, (i) steel/steel, (ii) DLC-coated ball/steel and (iii) steel/NCD-coated flat. Symmetric coated-contact configuration was not tested because this situation is not present in real engine parts. The friction tests were performed at $353 \mathrm{~K}\left(80{ }^{\circ} \mathrm{C}\right)$ with a maximum sliding speed of about $0.1 \mathrm{~m} \mathrm{~s}^{-1}$ for one-hour duration, no run-in period prior to the sliding experiment is performed. The maximum initial contact pressure was about $500 \mathrm{MPa}$ that corresponds to the maximal contact pressure between ring and cylinder in engine. In these sliding conditions, the thickness of the lubricant film, at the maximum speed, is equal to about $15 \mathrm{~nm}$ corresponding to a $\lambda$ ratio of about 1 . Prior to the experiment, both ball and flat specimens were cleaned in ultrasonic heptane bath in order to remove surface contaminants. An average friction coefficient for each sliding cycle was calculated from one thousand measurements of instantaneous friction coefficients recorded 
Table 1

Mechanical and physical properties of AISI 52100, NCD and DLC coatings.

\begin{tabular}{|c|c|c|c|c|c|c|c|}
\hline Materials & Thickness $(\mu \mathrm{m})$ & $\begin{array}{l}\text { Surface roughness } \\
(\mathrm{nm})\end{array}$ & H content (\%) & $\begin{array}{l}\mathrm{sp}^{3} / \mathrm{sp}^{3}+\mathrm{sp}^{2} \text { ratio } \\
(\%)\end{array}$ & Hardness (GPa) & $\begin{array}{l}\text { Biaxial modulus } \\
\text { (GPa) }\end{array}$ & Residual stresses (GPa) \\
\hline DLC coating & 4.5 & $\sim 15-20$ & $\sim 20$ & $25-30$ & $30 \pm 3$ & 220 & - \\
\hline NCD coating & 1.4 & $\leq 10$ & $<1$ & 75 & $74 \pm 2$ & 620 & $-3.2 \pm 0.4$ \\
\hline AISI 52100 substrate & - & $\sim 10$ & - & - & 9 & 210 & - \\
\hline
\end{tabular}

during the cycle. Each test was repeated four times under the same conditions in order to check the reproducibility of the friction experiment. The final worn volumes of the flat and the ball were evaluated from cross-sectional images of the wear tracks and from the width of the wear scars, respectively.

\subsection{Chemical and structural characterizations}

After the tribological experiments, the rubbed surfaces were analyzed by different surfaces analysis techniques to characterize the tribofilm that can be formed during sliding in lubricated conditions.

XPS surface analysis was carried out using an ULVAC-PHI Versa ProbeII spectrometer equipped with a monochromatized AlK $\alpha$ Xray source at $1486.6 \mathrm{eV}$ on neat additives and tribofilms. The size of the X-ray spot was $50 \mu \mathrm{m}$ and the energy scale was calibrated with reference to the C1s line at binding energy (BE) of $284.8 \mathrm{eV}$ (C-C. C-H). First, XPS analysis was performed by recording a survey spectrum on a wide range of $1200 \mathrm{eV}$ in order to identify all chemical elements. Afterwards, a scanning of the individual peaks in more detail over a smaller range of $15-25 \mathrm{eV}$ was undertaken. The detailed spectra of the elements identified are acquired to establish the different chemical states of the species and to perform a quantitative analysis using PHI multipack software. The chemical species corresponding to each binding energy have been attributed using standard materials, XPS handbook [35] and online database. XPS photo-peaks were fitted with a Shirley background, and the quantification is calculated with sensibility factors. All the parameters needed for the fitting such as the peak area ratio, the difference between doublets binding energies and the Full-Width at Half-Maximum (FWHM) were fixed to obtain the most appropriate chemical meaning. Before performing XPS analyses on the tribofilms, the friction specimens were cleaned by several immersions in pure heptane and then left in ultrasonic bath for 10 min to remove all the residual lubricant. To determine the chemistry of additives and binary mixtures, a drop of liquid was deposited on the relevant sample-holder mounted on a heat exchanger system provided with a thermocouple. Then, the system "sample holder + droplet of lubricant" was cooled down to a temperature of $-120{ }^{\circ} \mathrm{C}$ thanks to liquid nitrogen circulation under $\mathrm{Ar}$ gas pressure of about $10^{5} \mathrm{~Pa}$. This cooling took a few minutes (10 $\mathrm{min}$ ) before solid state was obtained. Then a pumping system providing a primary and secondary vacuum in the inlet chamber was started. A pressure $\leq 10^{-8} \mathrm{hPa}$ was needed before the sample holder was transferred from the inlet chamber into the ultrahigh vacuum XPS analysis chamber. Although the freezing of the liquid was relatively fast, some molecular reorganization at the surface is always possible. For these reasons, the chemical analysis by XPS on frozen liquids can hardly be considered as fully quantitative, especially in the case of the binary mixtures.

ToF-SIMS analyses were performed on a Physical Electronics TRIFT III ToF-SIMS instrument operated with a pulsed $22 \mathrm{keV} \mathrm{Au}{ }^{+}$ ion gun (ion current of around $2 \mathrm{nA}$ ) rastered over a $300 \mu \mathrm{m} \times 300 \mu \mathrm{m}$ area. No charge compensation was needed. Ion dose was kept below the static conditions limit. Data were analyzed using the WinCadence software. Mass calibration was performed on hydrocarbon secondary ions. Data were normalized to the total intensity minus hydrogen $\mathrm{H}^{-}$(because of its critical dependence on slight variations in the experimental settings), fluorine $\mathrm{F}^{-}$and chlorine $\mathrm{Cl}^{-}$(because both are ubiquitous contaminants) in negative mode. and to the total intensity minus hydrogen $\mathrm{H}^{+}$(same reason as in negative mode), sodium $\mathrm{Na}^{+}$, silicon $\mathrm{Si}^{+}$and potassium $\mathrm{K}^{+}$(because the 3 of them are contaminants) in positive mode. Standard deviations calculations were performed from 3 measurements in different areas.

The detailed microstructural characterization of the tribofilm formed on the steel counterparts was performed using FIB crosssections and a $200 \mathrm{kV}$ acceleration voltage Transmission Electron Microscope (JEOL 2010F HR-TEM) equipped with Energy Dispersive X-Ray Spectroscopy (EDX).

\section{Results and discussion}

\subsection{Friction and wear behaviors in the presence of base oil}

The different sliding contacts were lubricated with the two different base oils. PAO4 and mineral GrIII oil, in the operating conditions described previously. The friction curves obtained for these two base oils over 5000 cycles of friction are displayed in Fig. 2. For a given type of contact, there is no significant difference as a function of the base oil. It is observed that the $\mathrm{a}-\mathrm{C}: \mathrm{H} /$ steel friction pair exhibited a low coefficient of friction $(\mathrm{CoF})(0.05-0.06)$ in the presence of a single base oil compared to the other two types of contact, with CoF between 0.11 and 0.14 . This particular behavior is still not well understood but has already observed. For example, Equey et al. [23] also reported a very low friction coefficient $(\mathrm{CoF}=0.015)$ for a DLC/DLC contact lubricated with pure PAO. The authors suggested that this is related to the low shear strength intrinsic to carbon material. Another possible explanation would be the absence of oxygenated compounds in the base oils, so that the friction is running in the presence of inert environment and would then be dominated by the H-terminated carbon surfaces after a transfer of DLC material on the steel counterpart.

The low friction behavior was not obtained with NCD material in the presence of base oils without the additives. This can be related to the higher shear strength of this material avoiding the formation of a carbon transfer layer on the steel counterpart.

\subsection{Friction behavior in the presence of additivated base oil}

Fig. 3 compares the steady-state friction coefficients obtained for the different tribological contacts in the presence of PAO4 base oil additivated with various Mo-based additives combined to ZDDP. The steady-state friction coefficient is achieved after about the first 1000 sliding cycles. As the steady-state friction coefficients obtained with mineral GrIII oil are very similar to those obtained with the PAO4 oil, they are not reported here.

For steel/steel and steel/NCD friction pairs, the lubricants formulated with molybdenum-based compounds display a better 

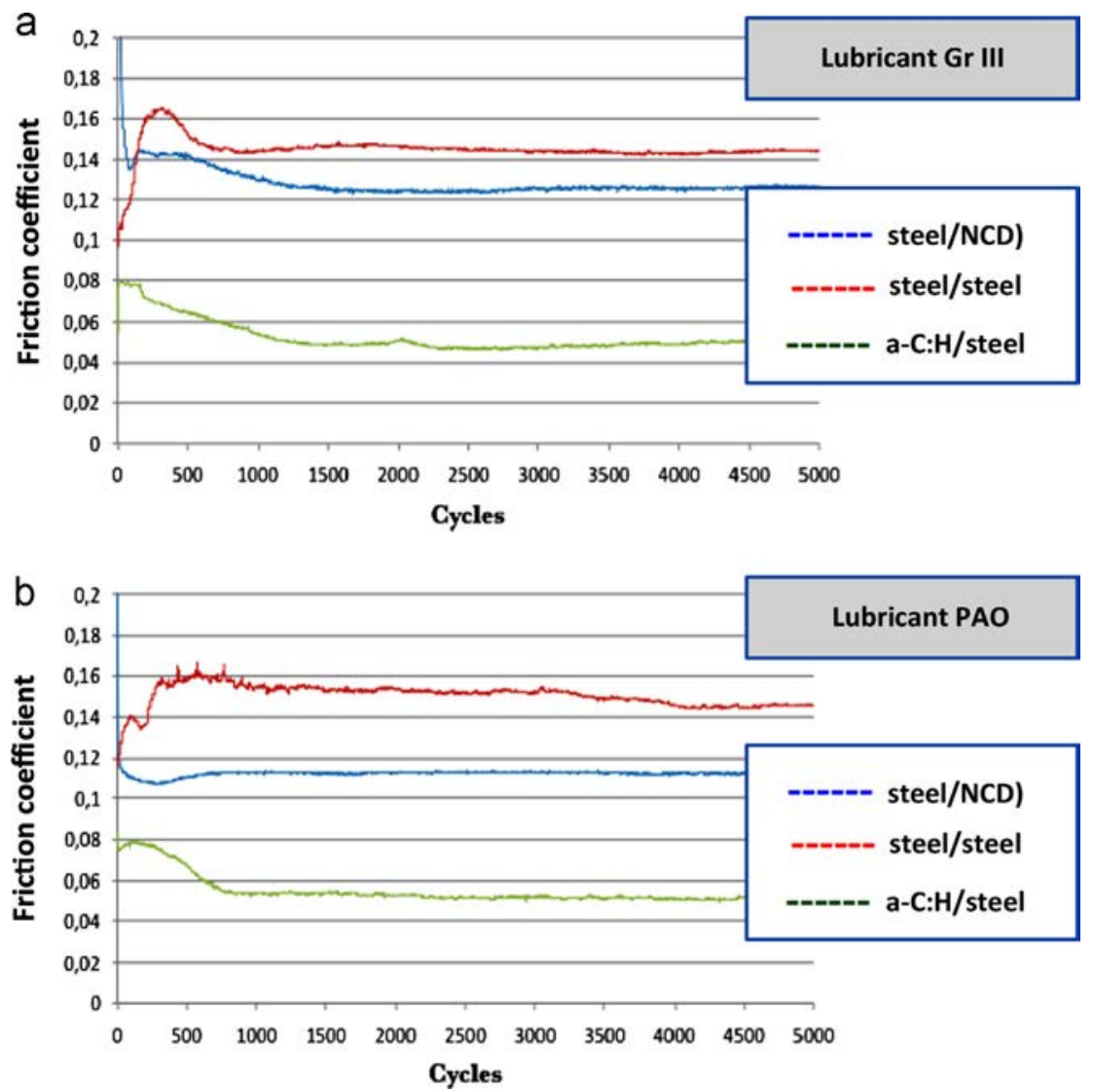

Fig. 2. Variation of friction coefficient obtained for three types of friction pairs steel/steel, a-C:H/steel and steel/NCD in the presence of (a) GRIII base oil and b) PAO4 base oil.

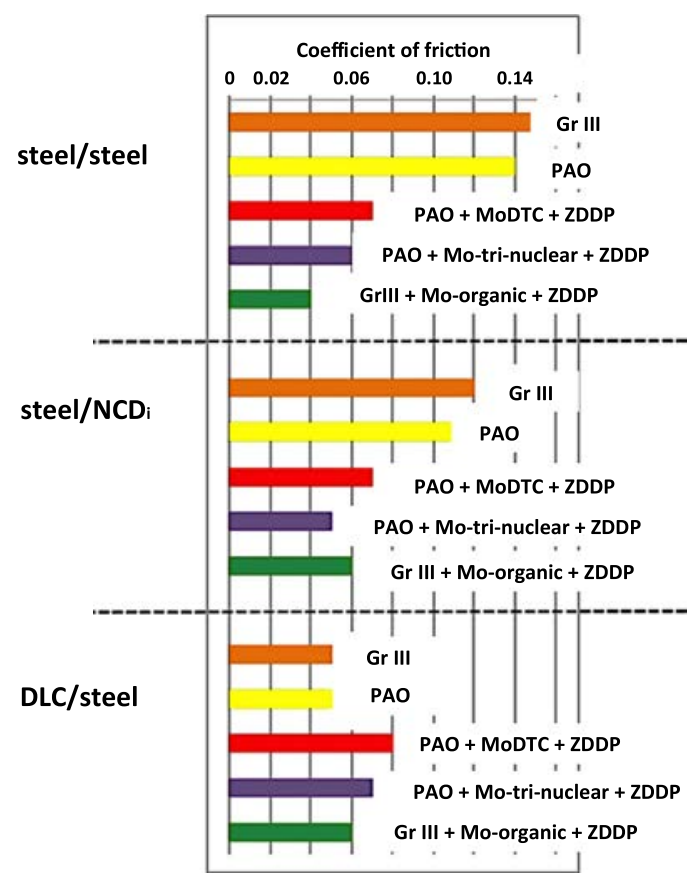

Fig. 3. Comparison of steady-state friction coefficients obtained for the three contacts, steel/steel. DLC/steel and steel/NCD in the presence of PAO4 and GrIII base oils containing molybdenum-based additives: Mo-organic, Mo-tri-nuclear and MoDTC.

ability to reduce friction in both base oils. CoF was indeed reduced by $70 \%$ for steel/steel and $50 \%$ for steel/NCD compared to the results obtained with the base oil alone. Moreover, the molybdenum content in the various mixtures being the same, i.e. $400 \mathrm{ppm}$, these compounds seems to be more efficient than traditional MoDTC additive in the tribological conditions used in this work. Indeed, for the steel/steel friction pair, a significant loss in friction of about $50 \%$ can be obtained compared with MoDTC, while for carbon-based coatings this loss was only about $20 \%$. For comparison, the friction reduction obtained in the presence of an organic friction modifier as GMO in similar conditions for steel/ steel contact is really less effective [36].

Moreover, the friction coefficient obtained with Mo-tri-nuclear additive is $30 \%$ higher than that obtained with Mo-organic for steel/steel contact. This result is surprising given that the Moorganic molecule needs to react with sulfur of ZDDP to form reducing friction $\mathrm{MoS}_{2} / \mathrm{MoS}_{2-x} \mathrm{O}_{x}$ sheets. One hypothesis that might be emitted is the thermodynamically unstable nature of Mo-organic molecule due to the presence of an octagonal cycle in the molecule. This could lead to rapid decomposition of the Moorganic molecule in the presence of catalytic iron surface, making possible a rapid formation of $\mathrm{MoS}_{2}$ sheets. It is also important to notice that an increase in friction coefficient was observed in the case of a-C:H/steel contact in comparison with PAO4 alone whatever the additivated base oils despite a shorter running-in period at the start of the test (data not shown).

Regarding the wear, even if the steady-state friction coefficients are slightly higher in the presence of additives for a-C:H/steel contact, the wear remained moderate in presence of ZDDP as shown by the width of wear tracks formed on the DLC-coated ball and steel flat that corresponds almost to the Hertzian diameter of the contact (results not shown here). Similar good wear wear resistance is found for steel/steel and steel/NCD friction pairs in the presence of additives in the base oil. 


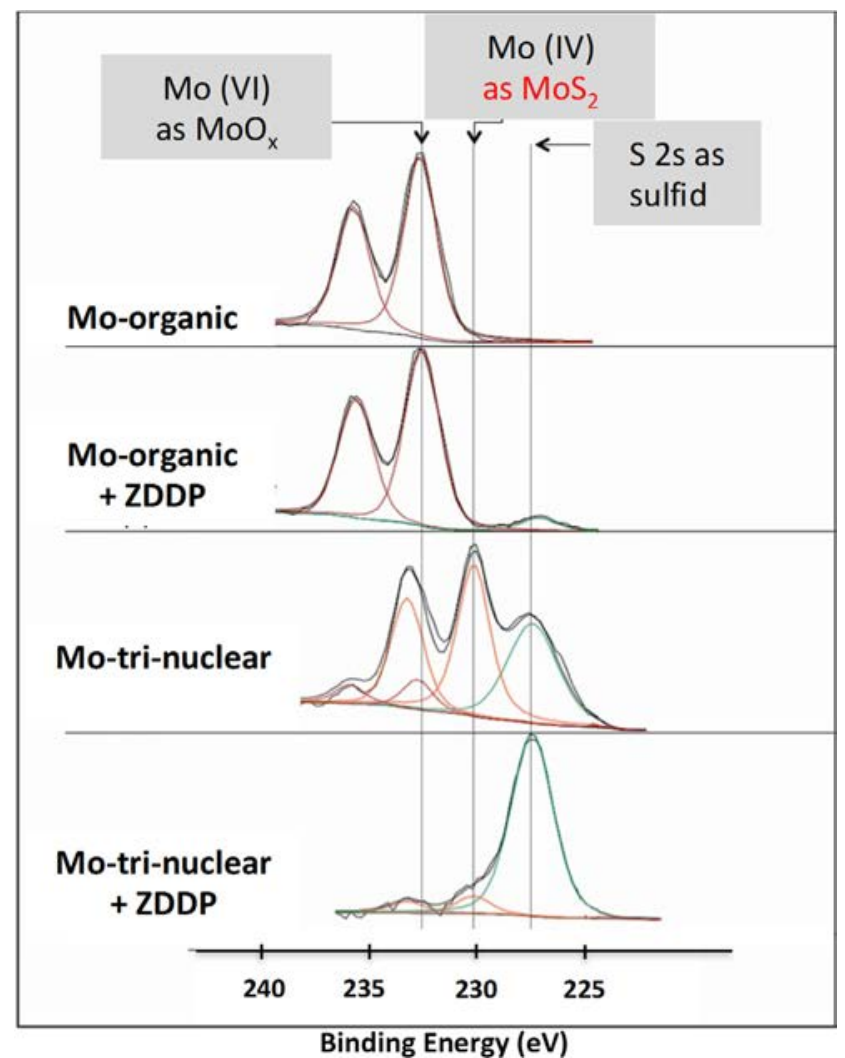

Fig. 4. Mo3d and S2s XPS photopeaks recorded for neat molybdenum-based additives and for the binary mixtures obtained by adding ZDDP.

\subsection{XPS analysis of liquid additives and binary additives mixtures}

In order to make easier the determination of the chemical nature of the tribofilms formed on the different rubbed surfaces, the liquid Mo-tri-nuclear and Mo-organic compounds were analyzed by XPS alone and in a binary mixture with ZDDP. The study of general spectra (not shown here) confirmed the presence of all the expected elements. Even if in theory, the Mo-tri-nuclear is oxygen free, a significant atomic percentage of oxygen was detected by XPS, about $14 \%$. Special attention was paid to the Mo3d, S2p, Zn2p and P2p photopeaks that are characteristic of additive elements. Investigation of Mo3d photopeak in Fig. 4 shows that the Mo-tri-nuclear exhibits two different chemical contributions: one oxidation state $\mathrm{VI}$ at $232.1 \mathrm{eV}$ binding energy that is associated with molybdenum trioxide $\mathrm{MoO}_{3}$ and another oxidation state IV at $229.6 \mathrm{eV}$, that can be mainly attributed to $\mathrm{Mo}_{3} \mathrm{~S}_{13}$ clusters present in the core of the molecule architecture. This result is in good agreement with the presence of the S2s contribution at about $226.6 \mathrm{eV}$ corresponding to sulfide. For Moorganic compound, Mo3d photopeak analysis shows a unique contribution attributed to Mo-O bonds at $232.1 \mathrm{eV}$ in agreement with the molecule formula (Mo at a VI oxidation state) and the absence of sulfur.

In the case of the binary mixture of Mo-organic with ZDDP, the Mo3d photopeak does not change much, it continues to display the oxidation state VI at $232.1 \mathrm{eV}$. However, the presence of the S2s peak of sulfur is also detected at about $226.6 \mathrm{eV}$ corresponding to sulfide chemical state, originating from sulfide ZDDP [36]. Therefore, the mixing with ZDDP even supplying thermal energy does not seem to change the initial oxidation state of molybdenum present in the Mo-organic additive.

For binary mixture Mo-tri-nuclear+ZDDP, it is difficult to conclude on a possible change of chemical state in the presence of

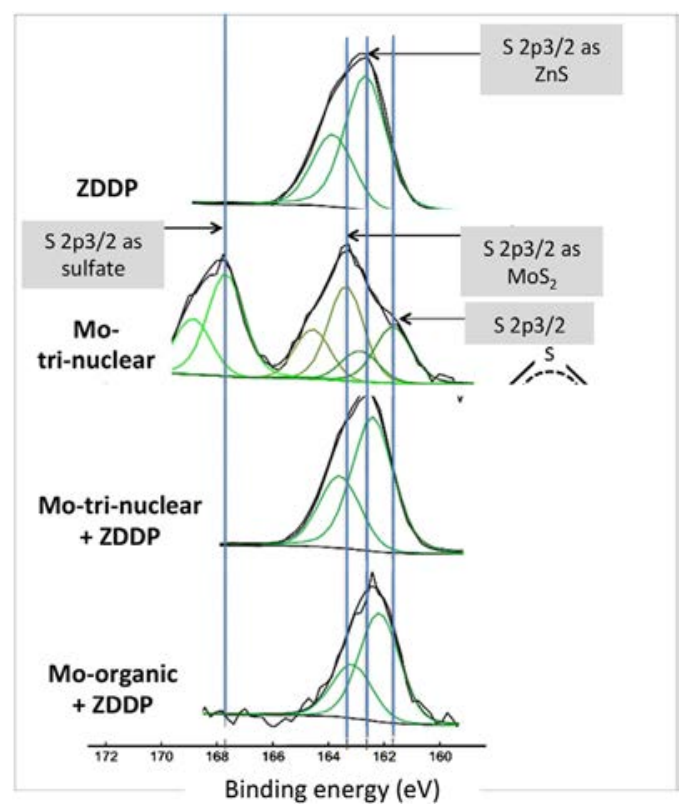

Fig. 5. S2p photopeaks recorded for molybdenum-based additives and for the binary mixtures obtained by adding ZDDP additive.

ZDDP because the signal of Mo3d is drastically decreased and the spectrum is dominated by the S2s peak of sulfur detected as a sulfide at about $226.6 \mathrm{eV}$, probably originating from ZDDP. This may be due to a preferential migration of ZDDP at the extreme surface of the droplet for the binary mixture with Mo-tri-nuclear during the freezing procedure. This observation is confirmed by the S2p photopeak presented in Fig. 5 where the S2p3/2 photopeak at $162.5 \mathrm{eV}$ indicates a chemical state corresponding to that of the sulfur in ZDDP, i.e. a zinc sulfide chemical bond. The sulfur in Mo-tri-nuclear compound appeared in three different chemical environments (Fig. 5): sulfate at $167.8 \mathrm{eV}$ confirming that this molecule has been oxidized, molybdenum sulfide and/or molybdenum oxysulfides at around $163.4 \mathrm{eV}$ and a last contribution at about $161.7 \mathrm{eV}$ that may be attributed to the sulfur atoms in the rings present at the periphery of the Mo-tri-nuclear molecule (see Fig. 1).

Once Mo-tri-nuclear is blended with ZDDP, there is only one unique chemical environment for sulfur characteristic of the zinc sulfide bonding in ZDDP at 162.5. This may be related to both the antioxidant effect of ZDDP that prevents the formation of sulfates and/or to a preferential migration of ZDDP at the extreme surface of the droplet during freezing.

\subsection{XPS analysis of tribofilms formed with Mo-based additives combined to ZDDP}

XPS analyses were performed for the three types of contact after friction experiments but wear scars were often difficult to clearly visualize in the case of carbon-involving contacts. Also, microscopic observations showed that in the presence of additives in the base oil, tribofilms preferably formed on the steel counterpart. Finally, potential interactions between lubricant additives and carbon coatings were studied in the case of NCD-coated flats that were more easy to analyze than balls especially as the friction results are similar in the presence of additives. For the three pairs, XPS analyses of flats were carried out by highlighting the differences between the tribofilm surface and chemical species adsorbed on the surface outside. For the sake of synthesis and clarity, only XPS signals of Mo will be studied in detail, as it is the main focus of interest in relation with the two additives studied here. 


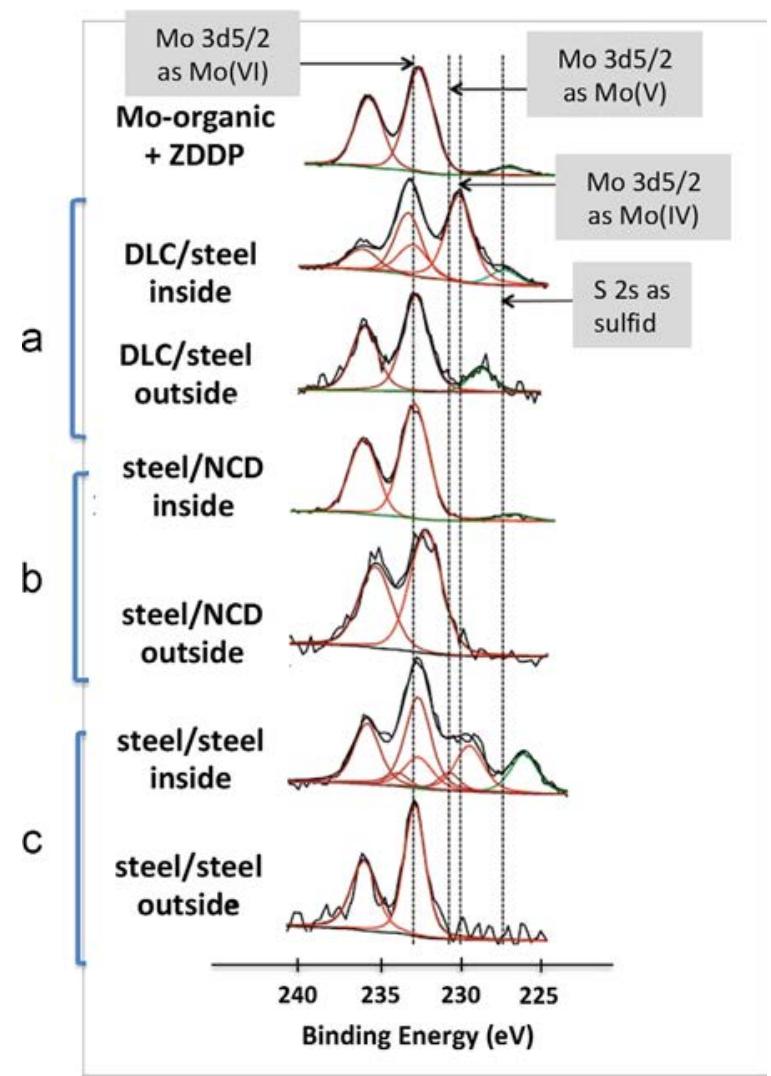

Fig. 6. XPS Mo3d and S2s photopeaks recorded inside and outside wear tracks obtained with the binary mixture containing Mo-organic and ZDDP for the three following types of contact: (a) a-C:H/steel; (b) steel/NCD and (c) steel/steel. XPS spectrum of the pure binary additives mixture is also provided at the top.

Please note that these XPS analyses give information on the chemical nature at the extreme surface of tribofilms (maximum thickness probed of about $10 \mathrm{~nm})$. In the next sections, some complementary top surface ( $\approx 1 \mathrm{~nm}$ ) ToF-SIMS characterization is also provided to discuss molecule integrity and possible contribution on the discussion about Mo chemical environment, while analysis performed by TEM/EDS on FIB cross sections gives information on the bulk structure of the tribofilms.

\subsubsection{Mo-organic +ZDDP mixture}

For a-C:H/steel contact, XPS analysis carried out on steel counterpart that rubbed against the hydrogenated DLC coating showed the appearance of new chemical contribution inside the tribofilm in comparison with the analysis of binary additives mixture (see Fig. 6a). This new contribution at $229.6 \mathrm{eV}$ corresponding to $\mathrm{Mo}$ (IV) can be mostly attributed to an oxisulfide, $\mathrm{MoS}_{2-x} \mathrm{O}_{x}$, as reported in the literature [18] than to pure $\mathrm{MoS}_{2}$. One could consider that the $\mathrm{Mo}(\mathrm{IV})$ in this tribofilm is almost $\mathrm{MoS}_{2}$ because of its binding energy is close to that of $\mathrm{MoS}_{2}\left(\mathrm{MoS}_{2}\right.$ varying between 228.5-229 [36]) but the S/Mo ratio is not consistent with this hypothesis. Indeed, the sulfur present as sulfide in the tribofilm is insufficient to form stoichiometric $\mathrm{MoS}_{2}$. This leads us to assume that $\mathrm{Mo}(\mathrm{IV})$ is not pure $\mathrm{MoS}_{2}$ but more related to the presence of a $\mathrm{MoS}_{2-x} \mathrm{O}_{x}$ compound.

Moreover, some authors have shown that the friction reduction is preserved by $\mathrm{MoS}_{2-x} \mathrm{O}_{x}$ when a low oxygen level, below $15 \%$, because of the $\mathrm{MoS}_{2}$ lamellar structure is preserved by substitution of sulfur by oxygen in the basal planes $[37,38]$. Regarding the other chemical elements characteristic of additives, $\mathrm{P}$ and $\mathrm{Zn}$, their XPS atomic percentages are very low, confirming the lower
Table 2

Oxidation state and concentration of chemical species characteristic of the additives detected by XPS on tribofilms formed with binary mixture containing Moorganic for different tribopairs.

\begin{tabular}{|c|c|c|c|c|c|c|}
\hline \multirow[t]{2}{*}{ Peak } & \multirow[t]{2}{*}{$\begin{array}{l}\text { Binding } \\
\text { energy }(e V)\end{array}$} & \multirow[t]{2}{*}{ FWHM (eV) } & \multicolumn{3}{|c|}{$\begin{array}{l}\text { Atomic concentration } \\
(\%)\end{array}$} & \multirow[t]{2}{*}{ Binding } \\
\hline & & & $\begin{array}{l}\text { DLC/ } \\
\text { steel }\end{array}$ & steel/NCD & $\begin{array}{l}\text { steel/ } \\
\text { steel }\end{array}$ & \\
\hline P2p & $133.3 \pm 0.3$ & $2 \pm 0.1$ & 1.5 & $<0.1$ & 2.7 & $\mathrm{P}-\mathrm{O}$ \\
\hline S2p & $\begin{array}{l}161.8 \pm 0.3 \\
167\end{array}$ & $\begin{array}{l}1.7 \pm 0.2 \\
1.8\end{array}$ & 3.5 & $\begin{array}{l}0.2 \\
<0.1\end{array}$ & 3.2 & $\begin{array}{l}\text { Sulfides } \\
\text { Sulfates }\end{array}$ \\
\hline Mo3d & $\begin{array}{l}229.3 \pm 0.3 \\
230.1\end{array}$ & $\begin{array}{l}2 \pm 0.1 \\
2\end{array}$ & 3.1 & & $\begin{array}{l}0.5 \\
0.2\end{array}$ & $\begin{array}{l}\mathrm{Mo}(\mathrm{IV}) \\
\mathrm{Mo}(\mathrm{V})\end{array}$ \\
\hline & $232.2 \pm 0.2$ & $2.2 \pm 0.3$ & 1.1 & 1 & 0.8 & $\mathrm{Mo}(\mathrm{VI})$ \\
\hline Zn2p & $1021.8 \pm 0.4$ & $2 \pm 0.2$ & 1.5 & 1.1 & 3.8 & $\mathrm{Zn}-\mathrm{O}, \mathrm{Zn}-\mathrm{S}$ \\
\hline N1s & $\begin{array}{l}399.3 \pm 0.3 \\
400.6\end{array}$ & $\begin{array}{l}2.9 \pm 0.3 \\
2.9 \pm 0.3\end{array}$ & 1.2 & 2 & 3.3 & $\begin{array}{l}\mathrm{N}-\mathrm{O} \\
\mathrm{C}-\mathrm{N}\end{array}$ \\
\hline
\end{tabular}

reactivity of organometallic additives for contacts involving carbon coatings in comparison with steel/steel ones (Table 2).

For steel/NCD contact, XPS analysis carried out on of the surface of the wear track formed on the NCD-coated flat revealed the presence of only one chemical state of molybdenum at $232 \mathrm{eV}$ binding energy, corresponding to oxidation state VI (Fig. 6b). This Mo (VI) contribution was also observed outside the wear track and can be derived from Mo-organic additive, $\mathrm{P}$ and $\mathrm{Zn}$ elements were also detected in very small amounts, less than $1 \mathrm{at} \%$. This result is not surprising because the high inertness of nanocrystalline diamond is responsible for a low reactivity of additives towards the surface. The low friction coefficient, 0.05-0.06, obtained for this carbon-involving contact in the presence of the Mo-organic + ZDDP mixture could then be related to the formation of a tribofilm on steel counterpart as shown previously with a-C:H/ steel contact.

For steel/steel contact, XPS analysis carried out on of the tribofilm formed on the steel flat revealed three different chemical states for molybdenum (Fig. 6c):

- Mo in the oxidation state VI at $232.1 \mathrm{eV}$ corresponding to $\mathrm{MoO}_{3}$ in the literature $[17,18,36]$.

- Mo in the oxidation state $\mathrm{V}$ at $230.2 \mathrm{eV}$ associated to Mo present in the molecules of traditional additives MoDTC and MoDTP $[11,14]$.

- Mo in the oxidation state IV at $229 \mathrm{eV}$ that can correspond to $\mathrm{MoS}_{2} / \mathrm{MoS}_{2-x} \mathrm{O}_{x}$ compounds. This peak is accompanied by the S2s sulfur signal at around $226 \mathrm{eV}$.

The quantitative data in Table 2 show that the overall amount of Mo in the tribofilm remains low (Mo atomic percentage was lower than 2\%). The $\mathrm{Mo}(\mathrm{IV}) / \mathrm{Mo}$ (VI) ratio was about 0.7. Concerning the other chemical elements detected in the tribofilm, it appears that S, P and $\mathrm{Zn}$ were observed in relatively moderate amounts in the tribofilm of the binary mixture Mo-organic+ZDDP, in the order of 3-4 at\%. Grossiord et al. [11] showed that the traditional MoDTC+ZDDP mixture leads to the formation of a tribofilm containing about 2 times more $\mathrm{P}$ and $\mathrm{Zn}$ than $\mathrm{S}$. On the other hand, the P2p photopeak at $133.3 \mathrm{eV}$ (not shown) is characteristic of a phosphate $\mathrm{P}-\mathrm{O}$ bond $[11,36]$. This seems to correspond rather to orthophosphates $\left(\mathrm{PO}_{4}{ }^{3-}\right)$ than a polyphosphate. This is confirmed by the 01s signal of oxygen which exhibited a contribution at $531.6 \mathrm{eV}$ (not shown), assigned to both $\mathrm{P}-\mathrm{O}$ and $\mathrm{P}=\mathrm{O}$ bonds in polyphosphates, much larger than that at $532.9 \mathrm{eV}$ assigned to $\mathrm{P}-\mathrm{O}-\mathrm{P}$ bonds in polyphosphates [11].

Outside the three different wear tracks analyzed, molybdenum is present at only oxidation state VI characteristic of the Mo-organic 


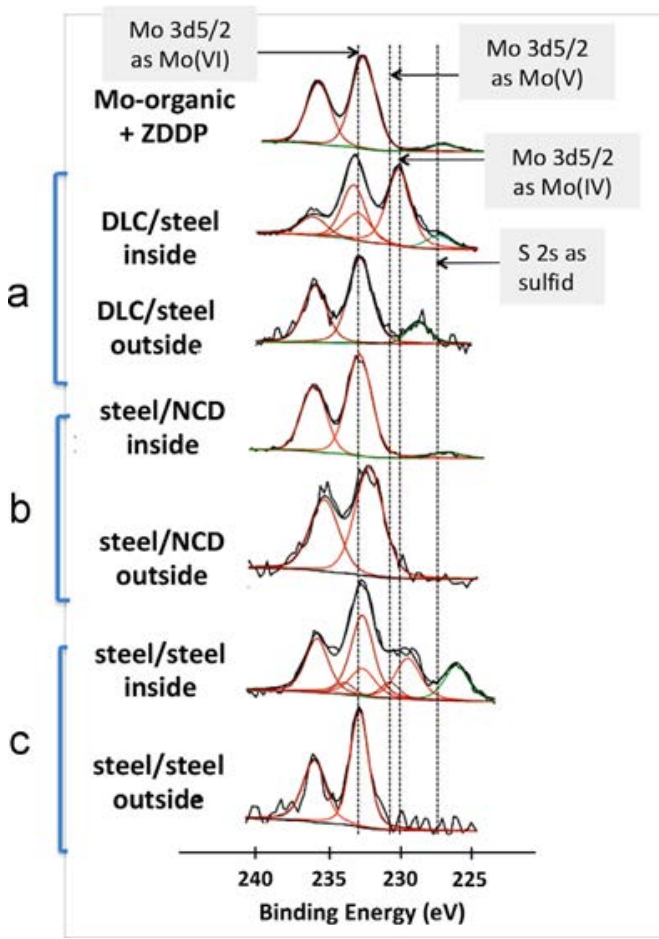

Fig. 7. XPS Mo3d and S2s photopeaks recorded inside and outside wear tracks obtained with the binary mixture containing Mo-tri-nuclear and ZDDP for the three following types of contact: (a) DLC/steel; (b) steel/NCD and (c) steel/steel. XPS spectrum of the pure binary additive mixture is also provided at the top.

molecule adsorbed on the surfaces. There is no other signal neither from $\mathrm{MoS}_{2}$ nor from oxysulfide compounds like $\mathrm{MoS}_{2-x} \mathrm{O}_{x}$, characteristic for an intermediate oxidation state. This result suggests that no early chemical reduction of the Mo-organic molecule occurred and underlines the fact that this molecule, even in the presence of ZDDP, seems to evolve only under shearing stresses and high contact pressure at $80^{\circ} \mathrm{C}$.

\subsubsection{Mo-tri-nuclear +ZDDP mixture}

For a-C:H/steel contact, $\mathrm{MoO}_{3}$ was detected on the tribofilm formed on the steel flat in amount somewhat close to that for Mo (IV) attributed to $\mathrm{MoS}_{2} / \mathrm{MoS}_{2-x} \mathrm{O}_{x}$ species (see Fig. 7a). This was not expected with this tri-nuclear molybdenum that is normally oxygen-free. Surprisingly, this compound, although rich in S, did not lead to the formation of a tribofilm exhibiting a $\mathrm{Mo}(\mathrm{IV}) / \mathrm{MoO}_{3}$ ratio greater than in the case of the mixture with Mo-organic for this contact (Tables 2 and 3). The chemical elements characteristic of ZDDP were detected on the steel in more significant atomic percentages for the binary Mo-tri-nuclear+ZDDP.

For steel/NCD contact, XPS analysis of the track formed on the NCD surface indicates the presence of molybdenum in the oxidation state (IV) (see Fig. 7b). However, the absence of a sufficient amount of sulfur ( $/ \mathrm{Mo}<2$, Table 3 ) and the binding energy at $229.3 \mathrm{eV}$ suggests that it is not pure $\mathrm{MoS}_{2}$ but rather $\mathrm{MoS}_{2-x} \mathrm{O}_{x}$. Similarly Mo(IV) was detected outside wear scar, but its atomic percentage was not significant, less than 0.1 at\% of Mo-tri-nuclear. This can be due to a weak adsorption of Mo-tri-nuclear molecule that initially contains molybdenum in oxidation state (IV).

For steel/steel contact, XPS analysis of the tribofilm formed on the steel flat indicated a certain amount of $\mathrm{Mo}(\mathrm{IV})$ as in $\mathrm{MoS}_{2-x} \mathrm{O}_{x}$ (about 3 at\%) (Fig. 7c). Studies by Grossiord et al. [11] showed that the traditional MoDTC+ZDDP mixture led to the formation of a tribofilm containing about 2 times less $\mathrm{Mo}(\mathrm{IV})$. It is also important to note the low content of molybdenum oxides at about $232 \mathrm{eV}$ unlike what was observed for the mixture with Mo-organic. This
Table 3

Oxidation state and concentration of chemical species characteristic of the additives detected by XPS on tribofilms formed with binary mixture containing Mo-trinuclear for different tribopairs.

\begin{tabular}{|c|c|c|c|c|c|c|}
\hline \multirow[t]{2}{*}{ Peak } & \multirow{2}{*}{$\begin{array}{l}\text { Binding energy } \\
(\mathrm{eV})\end{array}$} & \multirow{2}{*}{$\begin{array}{l}\text { FWHM } \\
(\mathrm{eV})\end{array}$} & \multicolumn{3}{|c|}{ Atomic concentration (\%) } & \multirow[t]{2}{*}{ Binding } \\
\hline & & & $\begin{array}{l}\text { DLC/ } \\
\text { steel }\end{array}$ & $\begin{array}{l}\text { steel/ } \\
\text { NCD }\end{array}$ & $\begin{array}{l}\text { steel/ } \\
\text { steel }\end{array}$ & \\
\hline P2p & $133.3 \pm 0.3$ & $2 \pm 0.1$ & 5.4 & 1.3 & 3.1 & $\mathrm{P}-\mathrm{O}$ \\
\hline S2p & $161.8 \pm 0.3$ & $1 . \overline{7} \pm 0.2$ & 6.4 & 2.3 & 8.4 & Sulfides \\
\hline Mo3d & $\begin{array}{l}229.3 \pm 0.3 \\
230.1\end{array}$ & $\begin{array}{l}2 \pm 0.1 \\
2\end{array}$ & 1.7 & 1.4 & 3.2 & $\begin{array}{l}\mathrm{Mo}(\mathrm{IV}) \\
\mathrm{Mo}(\mathrm{V})\end{array}$ \\
\hline & $232.2 \pm 0.2$ & $2.2 \pm 0.3$ & 1.2 & & 0.5 & $\mathrm{Mo}(\mathrm{VI})$ \\
\hline Zn2p & $1021.8 \pm 0.4$ & $2 \pm 0.2$ & 3.5 & 1.2 & 0.8 & $\begin{array}{l}\mathrm{Zn}-\mathrm{O} \\
\mathrm{Zn}-\mathrm{S}\end{array}$ \\
\hline N1s & $\begin{array}{l}399.3 \pm 0.3 \\
400.6\end{array}$ & $\begin{array}{l}2.9 \pm 0.3 \\
2.9 \pm 0.3\end{array}$ & 2 & 0.2 & & $\begin{array}{l}\mathrm{N}-\mathrm{O} \\
\mathrm{C}-\mathrm{N}\end{array}$ \\
\hline
\end{tabular}

result may be related to the structure of the molecule that is almost free of oxygen. As for the mixture based on Mo-organic and ZDDP, $\mathrm{P}$ and $\mathrm{Zn}$ elements were detected in relatively small amounts in the tribofilm, respectively around 1 and 3 at\%. Moreover, the characteristics elements coming from the additives (Mo, $\mathrm{S}, \mathrm{P}$ and $\mathrm{Zn}$ ) were not detected outside the tribofilm but only iron, oxygen and carbon were significantly present.

\subsection{Comparison of XPS data on the two binary mixtures tribofilms}

From the quantification of chemical elements detected at the surface of tribofilms for the 3 contacts and the Mo chemical states (described above), the following observations can be drawn for the two new Mo-based compounds:

- They both led to the formation of friction reduction disulfide/ oxisulfide materials in varying amounts only under the effect of pressure and shear in the contact;

- Mo-tri-nuclear was more effective in generating disulfide/oxisulfide whatever the contact type;

- The detection of iron by XPS in the tribofilm suggests that the tribofilm was thin;

- The new Mo compounds led to a friction behavior in combination with ZDDP at least as interesting as that of usual MoDTC under similar conditions and on the three types of contacts. As stated previously, the Mo-tri-nuclear+ZDDP binary mixture led to the formation of tribofilms exhibiting a higher $\mathrm{Mo}(\mathrm{IV}) / \mathrm{Mo}(\mathrm{VI})$ ratio regardless of the type of contact. However, the tribological performance of this binary mixture, although interesting, was not significantly better than the binary mixture based on Mo-organic.

\subsection{Complementary ToF-SIMS measurements}

XPS was the method of choice to study in detail the tribofilms and more especially the difference in chemical environment for Mo when comparing the various Mo-based additives in the various types of contact. ToF-SIMS can still bring some complementary information and results (not detailed here) were considering under the light of XPS main conclusions.

ToF-SIMS is more sensitive to the top surface of the tribofilm (information depth limited to a few monolayers) than XPS but still confirms the detection of iron (via $\mathrm{Fe}^{+}$) inside wear scar with still a higher relative intensity outside wear scar than inside. At the contrary, the relative intensity for $\mathrm{Zn}^{+}$was higher inside wear scar (data not shown), which confirms ZDDP is involved in the triboreactions. 

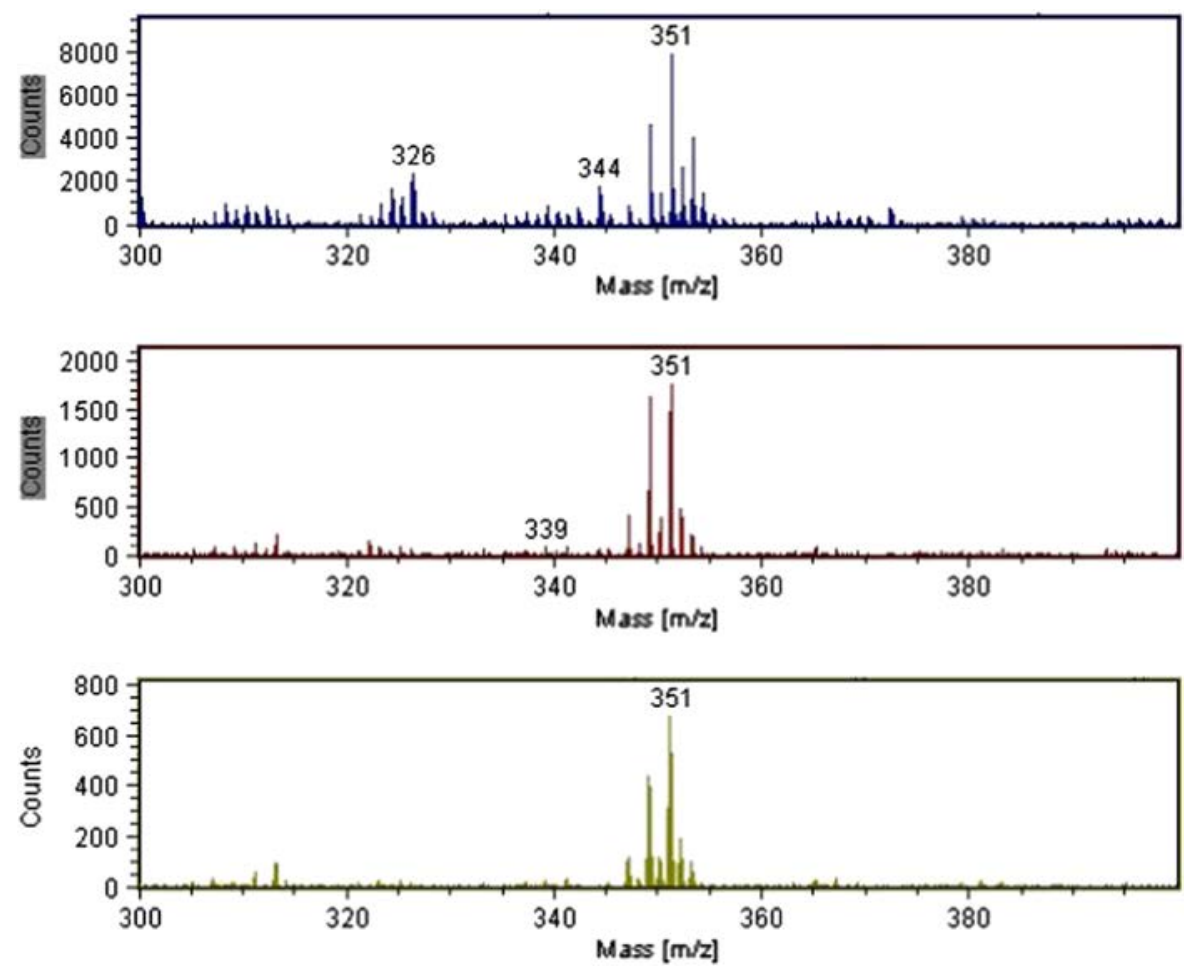

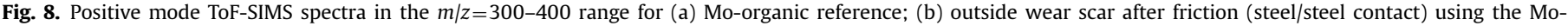
organic+ZDDP binary mixture; (c) inside wear scar after friction (steel/steel contact) using the Mo-organic + ZDDP binary mixture.

ToF-SIMS makes it possible to detect high mass molecular peaks. Fig. 8 displays the positive mode spectra in the $m / z=300-400$ range, showing that high mass peaks specific to Mo-organic can be observed in the reference sample, outside and inside wear scar. To a certain part, intact molecules are thus still detected after friction. On the other hand, as for XPS, even with a higher sensitivity. ToF-SIMS results confirmed that no significant Mo was detected at the surface of the outside wear scar in the case of the binary mixtures consisting of Mo-tri-nuclear and ZDDP (data not shown).

The key question around the Mo chemical environment was not an easy task in ToF-SIMS as $\mathrm{MoS}_{2}$ and $\mathrm{MoO}_{3}$ reference spectra exhibited quite similar Mo-based signatures (see Fig. 9(a) and (b)). This is due to very close $\mathrm{m} / z$ values from $\mathrm{O}_{2}$ (31.9898) and $\mathrm{S}$ (31.9721). Even in high mass resolution conditions, identifying the exact contributions from a mixture of these environments (as well as possible other ones) is not trivial.

It was still possible to identify differences in the ToF-SIMS negative mode reference spectra of Mo-organic and $\mathrm{MoS}_{2}$. Apart the expected signature for $\mathrm{S}^{-}$(significantly detected only for $\mathrm{MoS}_{2}$ ) (data not shown), some relative intensities appeared characteristic to Mo-organic (as the peak detected at $m / z=147$, which is related to the $\mathrm{Mo}+\mathrm{O}_{3}$ isotopic pattern) and $\mathrm{MoS}_{2}$ (as the peak detected at $m / z=162$, which is associated with the $M_{0} S_{2}$ isotopic pattern). When considering the spectra acquired outside and inside wear scar in the case of the steel/steel contact for the binary mixture consisting of Mo-organic and ZDDP, it was possible to make clear that, as expected, the spectrum acquired outside wear scar is identical to that of the Mo-organic reference while that acquired inside wear scar indicated a relative increase in intensity for the characteristic signature (in the displayed $m / z$ range) for $\mathrm{MoS}_{2}$. Thus, at least in the example displayed in Fig. 9, ToF-SIMS was able to confirm the hypothesis of tribo-reactions leading to the partial formation of $\mathrm{MoS}_{2}$ at the top surface. This was confirmed by the increase in the relative intensity for $\mathrm{S}^{-}$(data not shown). Finally, it can be noted that differences were observed for spectra acquired outside and inside wear scar when comparing intensity ratios of groups of peaks related to $\mathrm{Mo}+32\left(\mathrm{~S}\right.$ or $\left.\mathrm{O}_{2}\right)$ compared to $\mathrm{Mo}+64$ $\left(\mathrm{S}_{2}\right)$ and also $\mathrm{Mo}+48\left(\mathrm{SO}\right.$ or $\left.\mathrm{O}_{3}\right)$ compared to $\mathrm{Mo}+64\left(\mathrm{~S}_{2}\right)$. Both ratios were higher for the "inside wear scar" case. It was not directly related to observations in the reference spectra but indicated that reaction scheme is more complex at the top surface than simply leading to the sole $\mathrm{MoS}_{2}$.

\subsection{TEM observation and EDX analysis of tribofilms formed with Mo-based additives combined to ZDDP}

XPS and ToF-SIMS provided information on the extreme surface chemistry of tribofilms but not on their structure and thickness. To go further in the investigation of tribofilms obtained in the presence of the binary mixtures. TEM cross-sections were nanomachined using FIB technique. Tribofilms formed in the steel/steel contact were of prime interest, as they appeared thicker than in the previous XPS analyses.

Fig. 10 shows a TEM image of the tribofilm formed in the presence of the mixture containing Mo-organic and ZDDP. This highly amorphous film exhibited an average thickness of 25-35 nm. Its interface with the steel appeared quite hilly, suggesting a partial shear and wear of the native oxide layer on the steel surface before the tribofilm formation during the first cycles of friction corresponding to the running-in period. The high resolution TEM image (in the inset) confirmed the presence of some $\mathrm{MoS}_{2}$ sheets, of a length between about 2 and $10 \mathrm{~nm}$, dispersed in the matrix. EDX analysis performed on the entire thickness of the tribofilm indicated the absence of carbon inside the tribofilm and a relatively high level of oxygen (confirming XPS results). Iron was also detected inside the tribofilm, which is to be linked to the observation suggesting an interaction with the oxide layer, upstream of the formation of the tribofilm. This is also in agreement with the fact that there is no oxygen concentration at the interface between the steel and the tribofilm. It is also noted that $\mathrm{P}$ is present in small concentration relative to other elements such as $\mathrm{Zn}, \mathrm{S}$ and Mo, the latter two being particularly detected (data not shown). 

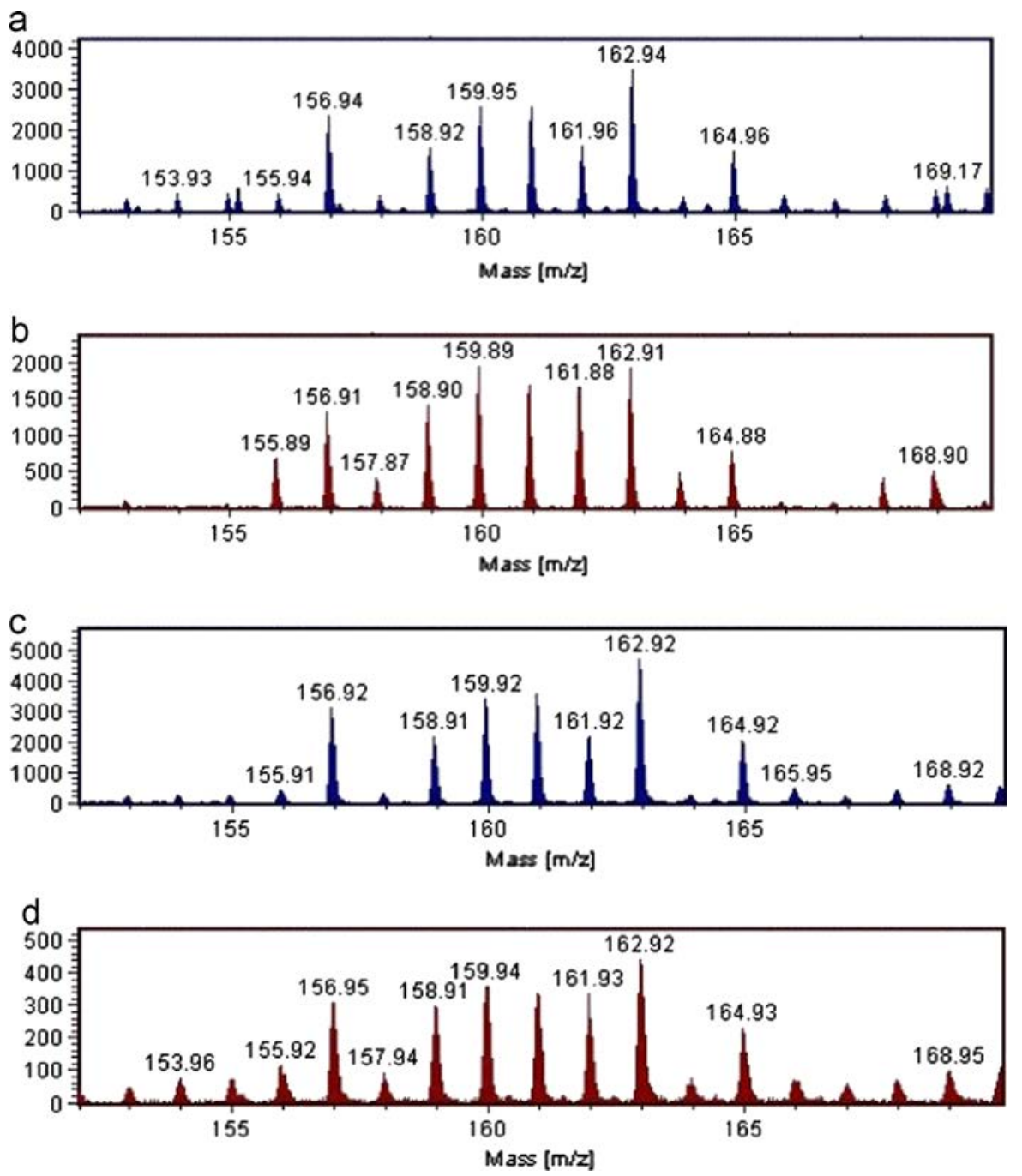

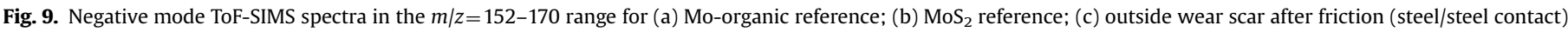
using the Mo-organic+ZDDP binary mixture (d) inside wear scar after friction (steel/steel contact) using the Mo-organic +ZDDP binary mixture.

Inset corresponds to the high-resolution TEM image of the sheets dispersed in the tribofilm.

Fig. 11 shows a TEM image of the tribofilm formed in the presence of the mixture containing Mo-tri-nuclear and ZDDP. Similarly to the previous tribofilm, it appeared amorphous but with a thickness of up to about $70 \mathrm{~nm}$, that is to say on average 2-fold higher than for the tribofilm in the case of Mo-organic. On the other hand, its interface with the steel happened to be much more regular with the presence of an oxide layer of a thickness of around $5 \mathrm{~nm}$. The high resolution image (in the inset) also showed the presence of well visible short sheets of $\mathrm{MoS}_{2}$, between 2 and $10 \mathrm{~nm}$ in length, and these were essentially identified at the top surface and oriented in the sliding direction. This can explain the higher Mo(IV) contribution detected by XPS on this tribofilm. EDX analyses (not shown here) performed on the entire thickness of the tribofilm derived from the Mo-tri-nuclear and ZDDP binary mixture indicated, as in the case of the Mo-organic, the absence of carbon and a high oxygen level, even higher than for the Moorganic and ZDDP binary mixture. Iron was also detected in large concentration throughout the tribofilm and $\mathrm{P}$ was in this case detected in larger amounts as compared to other elements such as $\mathrm{Zn}$ and Mo. Here, the tribofilm seemed to be essentially consisting of a phosphate glass/metal polyphosphates ( $\mathrm{Fe} / \mathrm{Zn}$ ) with, at its extreme surface, the presence of $\mathrm{MoS}_{2}$ sheets.
Inset corresponds to the high-resolution TEM image of the sheets dispersed in the tribofilm.

The tribofilm formed in the presence of the Mo-tri-nuclear+ZDDP mixture appears closer to the tribofilm formed with traditional additivation MoDTC and ZDDP. Indeed, several authors [11-14] have agreed that the tribofilm obtained in the case of the traditional additives is composed of two phases: a first phase consisting of a polyphosphate glass and a second phase consisting of amorphous carbon within which $\mathrm{MoS}_{2}$ sheets are dispersed. Overall, the interaction between these two additives is considered to be synergistic. ZDDP favors the formation of $\mathrm{MoS}_{2}$ from MoDTC. Part of the sulfur from ZDDP that contributes to form $\mathrm{MoS}_{2}$ can approach 40\%. ZDDP is antioxidant and prevents $\mathrm{MoS}_{2}$ to oxidize into $\mathrm{MoO}_{3}$. In the case of Moorganic+ZDDP mixture, the formation of $\mathrm{MoS}_{2}$ seems to be less efficient than with Mo-tri-nuclear as shown by XPS analyses although low friction is reached. Moreover, less phosphorus, responsible for polyphosphate glass formation, is detected in this case.

\section{Conclusion}

Two organic molybdenum-based friction modifier additives, Mo-organic and Mo-tri-nuclear, used in binary mixtures with ZDDP exhibited superior friction reducing properties compared to traditional MoDTC additive. This is verified for both steel/steel and 


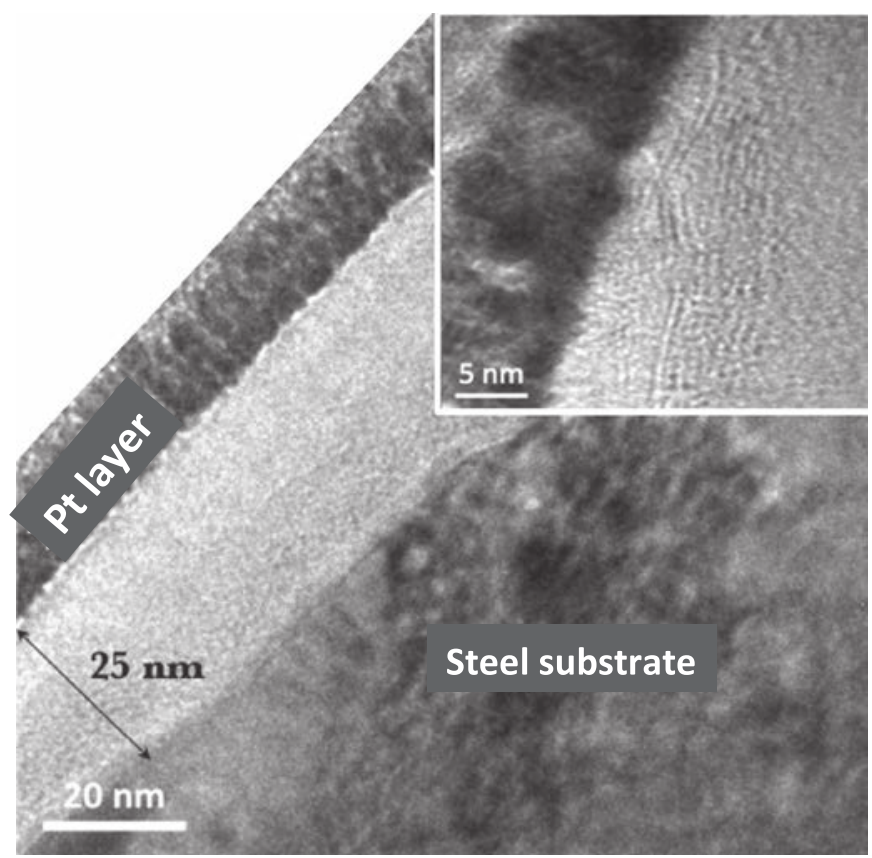

Fig. 10. TEM image of a FIB transverse cross-section of the tribofilm obtained for the steel/steel contact in the presence of the binary mixture containing Mo-organic and ZDDP.

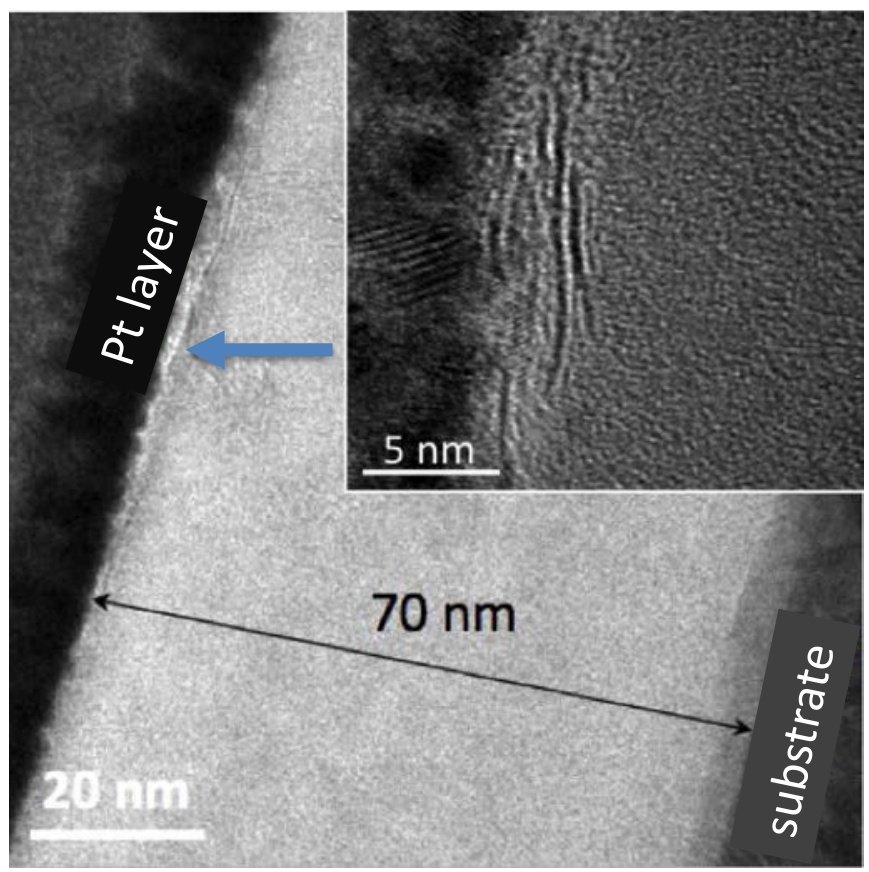

Fig. 11. TEM image of a FIB transverse cross-section of the tribofilm obtained for the steel/steel contact in the presence of the binary mixture containing Mo-trinuclear and ZDDP.

carbon-based coatings/steel friction pairs. Regarding the wear resistance, a good behavior is observed for all tribopairs in the presence of molybdenum-based friction modifier additives combined with ZDDP.

Surface XPS and ToF-SIMS analyses showed the formation of $\mathrm{MoS}_{2} / \mathrm{MoS}_{2-x} \mathrm{O}_{x}$ species on the steel counterparts for all tribopairs. NCD surface did not display these species and this can be explained by the inert nature of this type of surface. However, on the steel antagonist a tribofilm containing $\mathrm{MoS}_{2} / \mathrm{MoS}_{2-x} \mathrm{O}_{x}$ is formed explaining the low friction comparable to other contacts.
Most importantly, the present work highlights that the tribofilms obtained with the two additive mixtures for steel/steel contact display the presence of $\mathrm{MoS}_{2} / \mathrm{MoS}_{2-x} \mathrm{O}_{x}$ sheets homogeneously distributed inside an oxygen-rich amorphous matrix for the Moorganic and preferably placed at the outermost surface of the tribofilm for Mo-tri-nuclear. Surprisingly, tribofilms essentially consist of molybdenum, sulfur, zinc and oxygen and do not contain significant amount of carbon as in the case of traditional MoDTC additive. Results led to believe that they consist largely of a mixture of $\mathrm{MoS}_{2} / \mathrm{MoS}_{2-x} \mathrm{O}_{x}$, ZnS and metal oxides. Additional work is in progress to extend the formation of the solid-lubricant $\mathrm{MoS}_{2}$ / $\mathrm{MoS}_{2-x} \mathrm{O}_{x}$ sheets from these Mo-organic and Mo-tri-nuclear additives through synergistically action with other kinds of additives.

\section{Acknowledgement}

The authors wish to express their acknowledgement to the Agence Nationale de la Recherche for partial funding via the ANR Project EcoLub 09-MAPR-0015.

\section{References}

[1] Bowden FP, Taylor D. The friction and lubrication of solids: oxford classic text in the physical science. 2001 Chapter X.

[2] Russel JA, Campbell WE, Burton RA, Ku PM. Boundary lubrication behavior of organic films at low temperature. ASLE Trans 1965;8:48-58.

[3] Stackowiak GW, Batchelor AW. Engineering tribology. 3rd edition. Saint Louis, Missouri, U.S.A.: Butterworth-Heinemann: Elsevier; 2005 Chapter VIII.

[4] Choudhary RB. Action mechanisms of boundary lubrication additives: a review Part 1. Lubr Sci 2004:16(4):405.

[5] Papay AG. Antiwear and extreme-pressure additives in lubricants. Lubr Sci 1998;10:10-3.

[6] Martin JM. Antiwear mechanism of zinc diphiophosphate: a chemical hardness approach. Tribol Lett 1999;6:1-8.

[7] Graham J, Spikes H, Korcek S. The friction reducing properties of molybdenum dialkyldithiocarbamate additives: part I-factors influencing friction reduction. Tribol Trans 2001;44(4):626-36.

[8] Yue W, Sun XJ, Wang CB, Fu ZQ, Liu JJ. A comparative study on the tribological behaviors of nitrided and sulfur-nitrided 35CrMo steel lubricated in PAO base oil with MoDTC additive. Tribol Int 2011:44(12):2029-34.

[9] Grossiord C, Varlot K, Martin JM, Mogne TL, Esnouf C, Inoue K. MoS2 single sheet lubrication by molybdenum dithiocarbamate. Tribol Int 1998;31:737-43.

[10] Onodera T, Morita Y, Nagumo R, Miura R, Suzuki A, Tsuboi H, et al. A computational chemistry study on friction of h-MoS 2 . Part I. Mechanism of single sheet lubrication. J Phys Chem B 2009;113:16526-36.

[11] Martin JM, Grossiord C, Varlot K, Vacher B, Igarashi J. Synergistic effects in binary systems of lubricant additives: chemical hardness approach. Tribol Lett 2000;8(4):193-201.

[12] Kasrai MJ, Cutler JN, Gore K, Canning G, Bancroft GM, Tan KH. The chemistry of antiwear films generated by the combination of ZDDP and MoDTC examined by X-ray absorption spectroscopy. Tribol Trans 1998:41(1):69-77.

[13] Morina A, Neville A, Priest M, Green JH. ZDDP and MoDTC interactions and their effect on tribological performance-tribofilm characteristics and its evolution. Tribol Lett 2006:24(3):243-56.

[14] De Barros Bouchet MI, Bouchet J, Raoult I, Le Mogne T, Martin JM, Kasrai M, et al. Friction reduction by metal sulfides in boundary lubrication studied by XPS and XANES analyses. Wear 2003;254:863-70.

[15] Morina A, Neville A, Priest M, Green JH. ZDDP and MoDTC interactions in boundary lubrication - the effect of temperature and ZDDP/MoDTC ratio. Tribol Int 2006;39(12):1545-57.

[16] Kubo K, Nagakari M, Shitsmichi T, Motoyama K. The effect of ageing during engine running on the friction reduction performance of oil soluble molybdenum compounds. In: Proceedings of International Tribology Conference. Yokohama; 1995. p. 745-50.

[17] De Barros Bouchet MI, Martin JM, Le Mogne T, Bilas P, Vacher B, Yamada Y. Mechanisms of $\mathrm{MoS}_{2}$ formation by MoDTC in presence of ZnDTP: effect of oxidative degradation. Wear 2005;258:1643.

[18] De Feo M, Minfray C, De Barros Bouchet MI, Thiebaut B, Le-Mogne T, Vacher B, et al. Ageing impact on tribological properties of Mo-DTC containing base oil. Tribol Int 2015;92:126-35.

[19] De Barros Bouchet MI, Martin JM, Le Mogne T, Vacher B. Boundary lubrication mechanisms of carbon coatings by MoDTC and ZDDP additives. Tribol Int 2005;38:257-64.

[20] Podgornick B, Jacobson S, Hogmark S. Influence of EP additive concentration on the tribological behavior of DLC-coated steel surfaces. Surf Coat Technol 2005;191(2):357-66. 
[21] Kalin M, Vižintin J. A comparison of the tribological behaviour of steel/steel, steel/DLC and DLC/DLC contacts when lubricated with mineral and biodegradable oils. Wear 2006;261(1):22-31.

[22] Haque T, Morina A, Neville A, Kapadia R, Arrowsmith S. Non ferrous coating/ lubricant interactions in tribological contacts: assessment of tribofilm. Tribol Int 2007;40(10):1603-12.

[23] Equey S, et al. Reactions of zinc-free anti-wear additives in DLC/DLC and steel/ steel contacts. Tribol Int 2008;41(11):1090-6.

[24] Vengudusamy B, Green JH, Lamb GD, Spikes HA. Behaviour of MoDTC in DLC/ DLC and DLC/steel contacts. Tribol Int 2012;54:68-76.

[25] Hu JQ Wei XY, Dai GL, Fai YW, Xie F, Zong ZM. Tribological behaviors and mechanism of sulfur- and phosphorus-free organic molybdate ester with ZDDP. Tribol Int 2008;41:549.

[26] Guo ZG, Liu WM. Tribological behavior of molybdenum coordination compound without sulfur and phosphorus as oil additive for steel/steel contact. Tribology 2006;26(2):97-101.

[27] Yan L, Yue W, Wang C, Wei D, Xu B. Comparing the tribological behaviors of sulfur- and phosphorus-free organomolybdenum additive with ZDDP and MoDTC. Tribol Int 2012;53:50.

[28] Haque T, Morina A, Neville A. Influence of friction modifier and antiwear additives on the tribological performance of a non-hydrogenated DLC coating. Surf Coat Technol 2010;204:4001.
[29] Haque T, Morina A, Neville A. Effect of friction modifiers and antiwear additives on the tribological performance of a hydrogenated DLC coating. J Tribol 2010;132:032101.

[30] Shinyoshi T, Fuwa Y, Ozaki Y. Wear analysis of DLC coating in oil containing MoDTC. JSAE 20077103. SAE 2007; 01:1969.

[31] Patent US4889647 A.

[32] Patent US 6232276.

[33] De Barros MI, Serin V, Vandenbulcke L, Botton G, Andreazza P, Phaneuf MW. Diam Relat Mater 2002;11:1544-51.

[34] Aubry. O, Delfau JL, Met C, De Barros MI, Vandenbulcke L, Vovelle C. Molecular beam mass spectrometry analysis of gaseous species responsible for diamond deposition in microwave plasmas. J Phys IV 2002;12:75-84.

[35] J.F. Moulder, K.D. Bomben, P.E. Sobol, K.D. Bomben, Handbook of X-ray Photoelectron Spectroscopy, Perkin-Elmer Corp, Eden Prairie, MN, 1992.

[36] Kano M, Yasuda Y, Okamoto Y, Mabuchi Y, Hamada T, Ueno T. Tribol. Lett. 2005:18(2):245-51.

[37] Fleischauer PD, Lince JR. A comparison of oxidation and oxygen substitution in $\mathrm{MoS}_{2}$ solid film lubricants. Tribol int 1999;32(11):627-36.

[38] Martin JM. Superlubricity of molybdenum disulfide. In: Erdemir A, Martin JM editors. Superlubricity; 2007. p. 207-25. 